\title{
SMF Regimen
}

National Cancer Institute

\section{Source}

National Cancer Institute. SMFRegimen. NCI Thesaurus. Code C9668.

A chemotherapy regimen consisting of streptozocin, mitomycin, and fluorouracil that may be used in the treatment of pancreatic cancer. 